\title{
Muhammadiyah Green School di SMK Muhammadiyah 2 Turi Menuju Sekolah Adiwiyata
}

\author{
Septi Nur Wijayanti', Agus Nugroho Setiawan*2, Anisa Dwi Makrufi ${ }^{3}$ \\ 1Program Studi Hukum, Fakultas Hukum, Universitas Muhammadiyah Yogyakarta \\ 2Program Studi Agroteknologi, Fakultas Pertanian, Universitas Muhammadiyah Yogyakarta \\ ${ }^{3}$ Program Studi Pendidikan Agama Islam, Fakultas Agama Islam, Universitas Muhammadiyah Yogyakarta \\ *e-mail: septinurwijayanti73@gmail¹.com, agusns@umy.ac.id², anisadwimakrufi@fai.umy.ac.id ${ }^{3}$
}

\begin{abstract}
SMK Muhammadiyah 2 Turi launched the Adiwiyata school program, which is promoting knowledge and awareness about environmental conservation efforts among the student, and one way to make this happen is through the Muhammadiyah Green School (MGS). MGS is a concept that invites all stakeholders to form a lifestyle so that they care more about their environment. The problem is that the insights and skills of most of the stakeholders of SMKM 2 Turi on MGS are still limited. This community service program aims to increase knowledge and skills, and increase student and teacher awareness of the environment. This community service will be carried out in 2021 using a community development and participatory approach. The MGS program at SMK Muhammadiyah 2 Turi was conducted with several activities, i.e. coordination, focus group discussions, workshops, implementation, as well as mentoring and monitoring. With assistance from UMY, the MGS can improve the knowledge and skills of students and teachers in running MGS, the school environment is more conducive and productive, can become a medium for character education and cares for a clean and healthy environment, is able to provide space and learning materials for students, and be the first step towards Adiwiyata School.
\end{abstract}

Keywords: Adiwiyata school, Character education, Healthy environment, MGS, SMKM 2 Turi

\begin{abstract}
Abstrak
SMK Muhammadiyah 2 Turi mencanangkan program sekolah adiwiyata, yaitu sekolah yang peduli dan berbudaya lingkungan, dan salah satu cara untuk mewujudkannya melalui program Muhammadiyah Green School (MGS). MGS merupakan gerakan yang mengajak seluruh komponen untuk membentuk gaya hidup yang lebih peduli terhadap lingkungannya. Permasalahannya adalah wawasan dan ketrampilan sebagian besar stakeholder SMKM 2 Turi terhadap MGS masih terbatas. Program pengabdian kepada masyarakat ini bertujuan untuk meningkatkan wawasan dan keterampilan, serta meningkatkan kepedulian siswa dan guru terhadap lingkungan. Pengabdian pada masyarakat ini dilakukan pada tahun 2021 menggunakan pendekatan community development dan partisipatif. Program MGS di SMK Muhammadiyah 2 Turi sudah berjalan dengan beberapa kegiatan yaitu koordinasi, focus grup discussion, workshop, pelaksanaan, serta pendampingan dan monitoring. Dengan pendampingan dari UMY, program MGS dapat meningkatkan wawasan dan keterampilan guru dan siswa dalam menjalankan MGS, lingkungan sekolah lebih kondusif dan produktif, dapat menjadi media pendidikan karakter dan lebih peduli terhadap lingkungan yang sehat dan bersih, mampu menyediakan bahan dan ruang belajar bagi siswa, serta menjadi langkah awal menuju Sekolah Adiwiyata
\end{abstract}

Kata kunci: Lingkungan sehat, MGS, Pendidikan karakter, Sekolah adiwiyata, SMKM 2 Turi

\section{PENDAHULUAN}

Sekolah Menengah Kejuruan Muhammadiyah 2 Turi (SMKM 2 Turi) berada di Kapanewon Turi, Sleman, DIY di bawah koordinasi Majelis Dikdasmen Pimpinan Cabang Muhammadiyah (PCM) Turi. SMKM 2 Turi berdiri sejak tahun 1998 dan saat ini mempunyai 2 jurusan yang Teknik Audio Visual dan Keperawatan (dikdasmenpwmdiy, 2021), dengan visi "terwujudnya tamatan yang siap bekerja, mandiri, memiliki etos kerja, berbudaya dan bertaqwa kepada Allah SWT dalam menghadapi tantangan global" (Smkmuhaturi, 2021).

Dengan sumber daya yang dimilikinya baik sarana maupun prasarana serta guru dan siswa yang ada, SMKM 2 Turi melakukan berbagai kegiatan unggulan antara lain pelatihan Bahasa Jepang, pelatihan pembuatan produk kreatif Aloe vera, program rekayasa robotika, dan program 
pembuatan produk otomatis PLTS (Smkmuhaturi, 2021). Pendidikan di SMK Muhammadiyah 2 Turi dilaksanakan dengan mendasarkan pada konsep Pendidikan Islam dan mengemban amanah sebagai media dakwah amar ma'ruf nahi munkar.

Lingkungan pendidikan (sekolah) berperan penting sebagai media membangun karakter dan mengembangkan potensi diri melalui kegiatan di sekolah, baik yang bersifat kurikuler maupun ekstrakulikuler (Ginanjar, 2013). Oleh karenanya, lingkungan sekolah perlu dirancang agar mampu membangun karakter siswa yang baik (Mardliyah et al., 2016; Ginanjar, 2013), mampu menjadi sumber belajar (Haryati, 2016; Ikhsan et al., 2017) dan menciptakan suasana pendidikan yang kondusif sehingga peserta didik dapat mengembangkan potensi dirinya (Rahmah, 2020). Untuk mendukung pendidikan karakter di sekolah diperlukan 4 komponen penting yaitu kebijakan sekolah, kurikulum, partisipasi berbasis aktivitas, dan sarana prasarana pendukung (Sagala, 2019).

Untuk mendukung pencapaian visi dan misinya, SMKM 2 Turi mencanangkan program sekolah adiwiyata. Berdasarkan Permen LHRI No. 05 Tahun, Program Adiwiyata merupakan program untuk mewujudkan sekolah yang lebih peduli dan berbudaya lingkungan, sedangkan Sekolah Adiwiyata adalah sekolah yang peduli dan berbudaya lingkungan (Wijaya, 2019). Program Adiwiyata bertujuan antara lain untuk mengubah perilaku masyarakat menjadi peduli lingkungan, menciptakan suasana dan kondisi pembelajaran menjadi lebih nyaman dengan lingkungan yang bersih, asri, dan sehat, mengembangkan suasana kebersamaan untuk meningkatkan persatuan dan kesatuan, serta meningkatkan penghematan energi dan sumber daya (Wijaya, 2019). Program Adiwiyata sejalan dengan instrumen HAM Internasional secara garis besar memberikan pengakuan terhadap hak atas lingkungan yang sehat (Ashabul, 2013). Lingkungan yang sehat menjadi kebutuhan dasar manusia karena merupakan tempat berlindung serta menumbuhkan kehidupan yang baik secara psikologis, fisik, dan sosial (Sajiwo, 2019).

Salah satu cara untuk mewujudkan Sekolah Adiwiyata dan atmosfer pendidikan yang kondusif di SMKM 2 Turi adalah program Muhammadiyah Green School (MGS). MGS bukan sekedar gerakan penghijauan, namun merupakan gerakan yang mendorong seluruh komponen masyarakat untuk membentuk gaya hidup yang lebih peduli terhadap lingkungannya. Sekolah harus mempunyai komitmen dan secara sistematis perlu mengembangkan program-program yang dapat menginternalisasikan nilai-nilai baik ke dalam semua aktivitas sekolah. Pendidikan tidak lagi dijadikan sebagai beban, namun harus memberikan makna kehidupan secara baik, membebaskan, dan menyenangkan, sehingga mendorong peserta didik untuk bertanggung jawab pada lingkungannya dan memberdayakan dirinya (Sumarmi, 2008).

Permasalahannya adalah kepedulian terhadap lingkungan yang bersih dan sehat, serta pengetahuan, wawasan dan ketrampilan sebagian besar stakeholder SMKM 2 Turi tentang MGS masih terbatas. Oleh karena itu perlu dilakukan program pengabdian kepada masyarakat yang bertujuan untuk meningkatkan wawasan dan keterampilan guru dan siswa SMKM 2 Turi dalam menjalankan MGS. Program MGS ini diharapkan dapat menjadi media untuk lebih peduli terhadap lingkungan yang sehat dan bersih, sebagai media pendidikan karakter, menciptakan atmosfer pendidikan yang kondusif, menyediakan ruang dan sumber belajar bagi siswa, serta meningkatkan kompetensi guru dan siswa sehingga terwujud Sekolah Adiwiyata.

\section{METODE PELAKSANAAN}

Pengabdian pada masyarakat dilakukan dengan pendekatan community development dan partisipatif. Pendekatan community development merupakan pendekatan yang berorientasi pada upaya-upaya pemberdayaan masyarakat dengan menjadikan masyarakat sebagai subyek dan sekaligus obyek pembangunan demi kepentingan mereka sendiri. Community development dapat memberdayakan potensi yang masyarakat sehingga dalam jangka panjang dapat memberi manfaat bagi masyarakat itu sendiri (Triyono, 2014; Rinaldy et al., 2017). Pendekatan partisipatif 
merupakan pendekatan yang berorientasi pada peningkatan peran serta masyarakat secara langsung dalam proses dan pelaksanaan kegiatan (Muslim, 2007; Asnudin, 2010).

Mitra sasaran program pengabdian pada masyarakat adalah SMKM 2 Turi, yang secara teknis melibatkan berbagai komponen yang ada, antara lain PCM Turi, Majelis Dikdasmen PCM Turi, guru dan siswa SMKM 2 Turi. SMKM 2 Turi merupakan mitra sasaran langsung yang akan ditingkatkan kinerjanya. PCM Turi sebagai sebagai organisasi Muhammadiyah di tingkat kecamatan bertanggung jawab terhadap semua amal usaha Muhammadiyah. Majelis Dikdasmen merupakan majelis di PCM yang mengelola semua sekolah Muhammadiyah di PCM Turi sehingga keberadaannya sangat penting dalam program ini.

Program pengabdian pada masyarakat dilakukan menggunakan beberapa metode, yang meliputi pendidikan masyarakat, difusi ipteks, pelatihan, dan konsultasi. Pendidikan masyarakat (penyuluhan) dilakukan dengan mengumpulkan mitra sasaran yaitu Kepala Sekolah, guru dan siswa untuk mengikuti penyuluhan Muhammadiyah Green School, yang dilakukan oleh Tim Pelaksana. Pelatihan dilakukan setelah penyuluhan untuk memberikan ketrampilan kepada mitra sasaran dalam menjalankan dan mengelola Muhammadiyah Green School, yang semuanya dilakukan oleh Tim Pelaksana. Praktek (Difusi iptek) dilakukan setelah penyuluhan dan pelatihan, dengan bimbingan oleh Tim Pelaksana. Konsultasi dilakukan pada saat pembinaan dan pendampingan mitra sampai berhasil menjalankan dan mengelola $M G S$ sampai berhasil. Untuk mendapatkan keberlanjutan, program Muhammadiyah Green School di SMKM 2 Turi dirancang kegiatan dalam beberapa tahapan (Gambar 1).

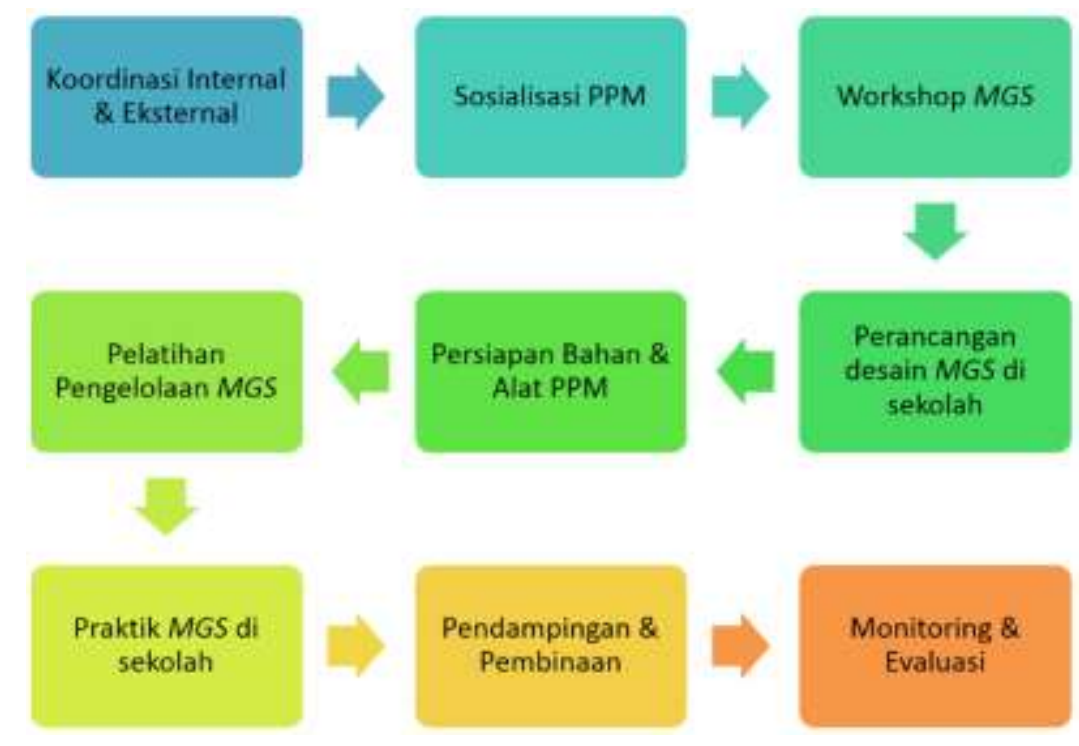

Gambar 1. Tahapan pengabdian kepada masyarakat MGS di SMKM 2 Turi

Pada tahapan awal dilakukan koordinasi internal maupun eksternal. Koordinasi internal dilakukan oleh Tim Pelaksana, sedangkan koordinasi eksternal antara Tim Pelaksana dengan mitra sasaran yaitu SMKM 2 Turi. Setelah ada kesepakatan, selanjutnya dilakukan sosialisasi kegiatan untuk memberikan gambaran secara umum program pengabdian kepada masyarakat yang akan dilakukan, dan workshop tentang $M G S$ dengan fasilitator Tim Pelaksana. Setelah mitra mendapatkan wawasan dan pengetahuan, selanjutnya dilakukan persiapan berbagai peralatan dan bahan yang akan digunakan untuk implementasi $M G S$ di sekolah. Implementasi $M G S$ dilakukan sesuai dengan kebutuhan dan sumber daya sekolah. Untuk mendapatkan keberlangsungan dan keberhasilan program, dilakukan pendampingan dan pembinaan dengan mendatangi mitra secara periodik, serta dilakukan monitoring dan evaluasi. 


\section{HASIL DAN PEMBAHASAN}

Secara umum program MGS dapat dikembangkan seperti halnya program green school pada umumnya melalui green curriculum, green community, green school, dan green culture (Majumdar, 2010), namun pelaksanaan MGS di SMKM 2 Turi saat ini lebih dititikberatkan melalui kegiatan green school dan green culture. Green school dilakukan dengan pengelolaan sumber daya sekolah seperti halaman sekolah, air, sampah, dan sebagainya. Lingkungan sekolah ditata sedemikian rupa sehingga dapat menjadi sarana belajar dan laboratorium alam. Air, energi dan sampah/ limbah dikelola dengan pembiasaan hemat sumber daya. Green culture dikembangkan dengan semangat "kebersihan adalah sebagian dari Iman" melalui program-program pendidikan nilai, etika, sikap, dan perilaku, misalnya membiasakan peduli lingkungan yaitu membuang sampah ditempatnya, mensukseskan program pengurangan, menyediakan kantin dan koperasi sekolah yang menjual makanan tidak dibungkus plastik, dan sebagainya.

Program pengabdian pada masyarakat di SMKM 2 Turi dilakukan mulai bulan FebuariMei 2021. Beberapa kegiatan yang dilakukan antara lain koordinasi, focus group discussion (FGD), workshop, implementasi $M G S$ di sekolah, pembinaan, serta monitoring dan evaluasi. Koordinasi internal dilakukan oleh Tim Pelaksana untuk menyamakan persepsi dan mendiskusikan langkahlangkah kegiatan. Koordinasi eksternal antara Tim Pelaksana dengan Kepala SMKM 2 Turi sebagai mitra dilakukan untuk membicarakan teknis pelaksanaan program dan membuat kesepakatan bersama.

Selanjutnya diadakan sosialisasi program pengabdian pada masyarakat dalam bentuk focus group discussion yang diikuti perwakilan guru SMKM 2 Turi sebagai pendamping kegiatan. Topik yang dibicarakan dalam FGD antara lain tujuan PPM, gambaran umum MGS, tahapan kegiatan, kepesertaan, serta kebutuhan alat dan bahan. Selain itu, juga disampaikan potensi sumber daya lingkungan dan sumber daya manusia, serta kegiatan-kegiatan dalam mengelola lingkungan sekolah yang mengarah pada MGS yang sudah dilakukan (Gambar 2).
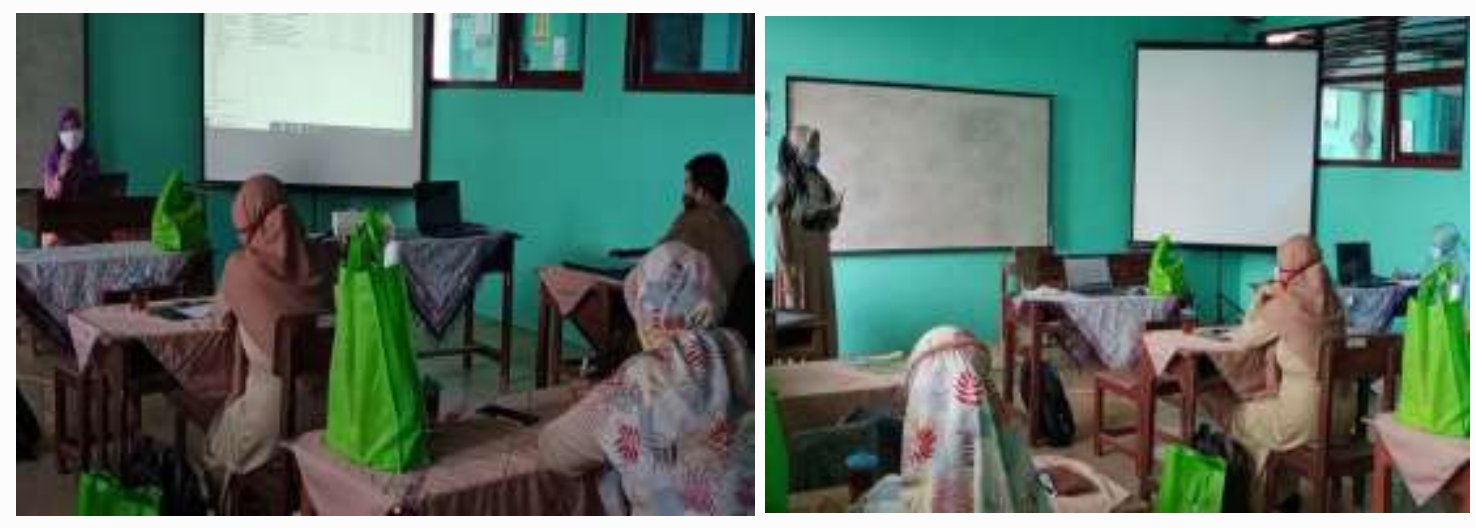

Gambar 2. Focus Group Discussion tentang Muhammadiyah Green School

Untuk meningkatkan pengetahuan, wawasan, pengalaman dan memberikan contoh pelaksanaan green school, selanjutnya diadakan workshop $M G S$ yang diikuti oleh Kepala Sekolah dan guru SMKM 2 Turi, Pimpinan Cabang Muhammadiyah (PCM) Turi, dan Majelis Dikdasmen PCM Turi (Gambar 3a), serta nara sumber dari Tim Pelaksana dan Maria Febriana dari Jogja Green School (Gambar 3b). Materi yang disampaikan dalam workshop antara lain MGS sebagai usaha untuk menciptakan lingkungan yang bersih dan sehat, teknologi dalam mendukung pelaksanaan $M G S$, dan pengalaman pelaksaan green school. Karena masih dalam masa pandemi, kegiatan workshop dilakukan dengan tetap menerapkan protokol kesehatan yang ketat seperti menggunakan masker, menjaga kebersihan dengan mencuci tangan dan memakai handsanitizer, menjaga jarak, serta tidak saling berjabat tangan (Menkes, 2020). 


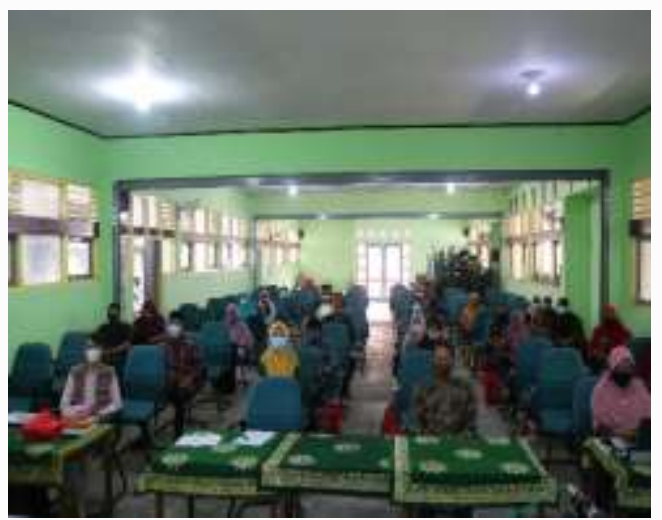

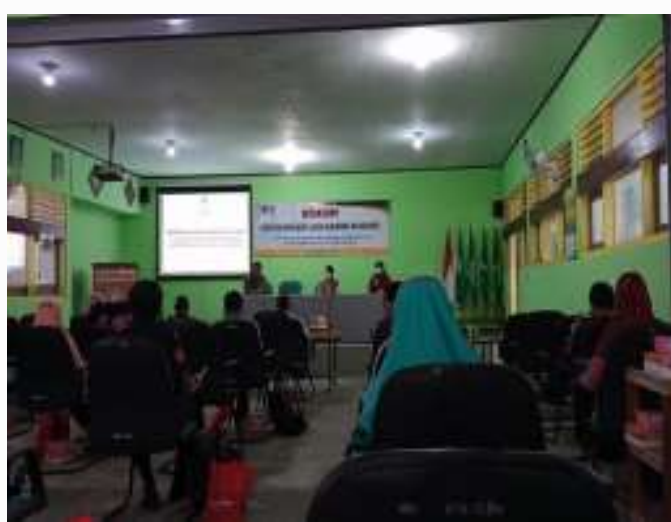

$\mathrm{b}$

Gambar 3. Workshop MGS di SMKM 2 Turi; peserta (a), nara sumber (b)

Tim Pelaksana menjelaskan bahwa lingkungan yang bersih dan sehat merupakan kebutuhan pokok manusia dan menjadi setiap warga negara, sehingga lingkungan sekolah sebagai bagian dari lingkungan hidup juga perlu didesain dan dikembangkan agar dapat menjadi tempat berlindung dan menumbuhkan kehidupan yang baik. Untuk mewujudkan lingkungan yang sehat dan sekaligus mengajarkan siswa untuk peduli lingkungan dapat dilakukan melalui program Muhammadiyah Green School. MGS bukan sekedar gerakan penghijauan di sekolah Muhammadiyah, namun merupakan gerakan yang mengajak semua komponen sekolah Muhammadiyah untuk menjalankan gaya hidup yang lebih peduli terhadap lingkungan, dengan dilandasi semangat Muhammadiyah dalam berdakwah yaitu amar ma'rif nahi munkar yang menjadi pembeda dengan program green school di sekolah pada umumnya. Selain itu, Maria Febriana, SPd. dari Jogja Green School memaparkan pengalaman pelaksanaan green school di sekolahnya. Jogja Green School sebagai pusat kegiatan belajar mengajar (PKBM) mendesain sekolahnya berbasis alam dan menekankan pendidikan karakter dengan semangat kebersamaan, bahkan menerima dan memfalitasi siswa berkebutuhan khusus untuk belajar bersama (inklusi). Berbekal dari hasil workshop tersebut, selanjutkan sekolah dengan didampingi oleh Tim Pelaksana menyusun model MGS sesuai dengan potensi yang ada.

Implementasi MGS di SMKM 2 Turi dilakukan dengan penataan lingkungan dan pengembangan kegiatan pendukung MGS. Lingkungan SMKM 2 Turi terdiri dari gedung ruang kelas, perkantoran, laboratorium/ruang praktik, poliklinik, kantin, dan halaman. Gedung yang ada dibangun berderet dengan bagian tengah berupa halaman sekolah, yang biasa digunakan untuk upacara bendera, olahraga atau kegiatan mengumpulkan banyak orang. Gedung yang ada di SMKM 2 Turi dicat berwarna hijau dan halaman sekolah ditanami hamparan rumput hijau dengan perawatan yang intensif dan berkelanjutan sehingga menghasilkan lingkungan sekolah dengan nuansa hijau yang menimbulkan kesan sangat asri (Gambar 4a).

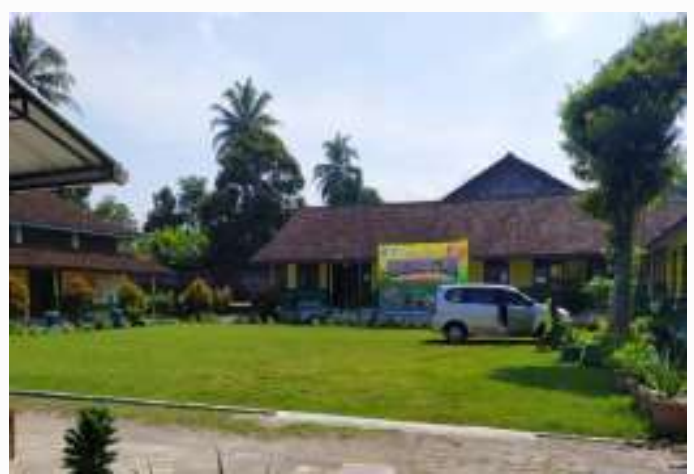

a

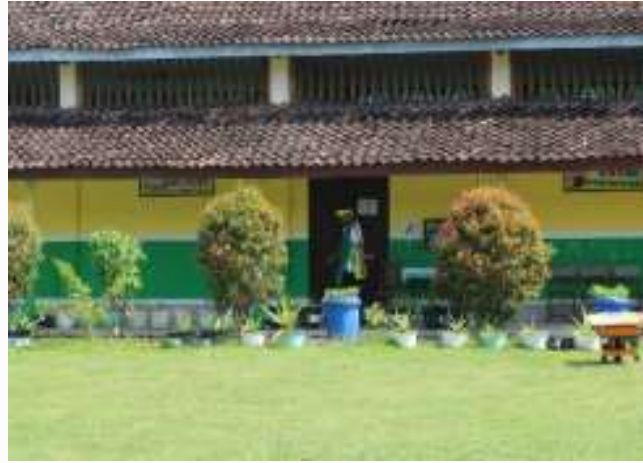

b

Gambar 4. Lingkungan sekolah SMKM 2 Turi yang asri dengan nuansa warna hijau 
Di sekeliling halaman SMKM 2 Turi juga ditanam berbagai jenis tanaman baik, antara lain tanaman hias terutama pucuk merah (Gambar 4b), tanaman buah berupa mangga, kelengkeng dan anggur, serta tanaman obat dan lidah buaya. Tanaman hias dan buah yang merupakan tanaman tahunan ditanam langsung di tanah karena dapat tumbuh menjadi besar dan tinggi sehingga membutuhkan media pertumbuhan akar yang dalam, sedangkan tanaman obat dan lidah buaya ditanam di pot plastik (Gambar 5a) karena meskipun berumur panjang tetapi habitus tidak besar dan perakarannya relatif pendek. Tanaman obat yang ditanam dipilih beberapa jenis tanaman obat yang dapat dipergunakan untuk pertolongan pertama atau untuk penyakit yang ringan (Sari et al., 2019). Keberadaan tanaman obat di lingkungan sekolah sangat penting, terutama SMKM 2 Turi mempunyai jurusan Keperawatan. Untuk mendukung dan memberikan semangat pada siswa dan guru dalam menajalankan MGS, juga dilakukan kampanye dengan memasang spanduk dan standing banner (Gambar 5b).

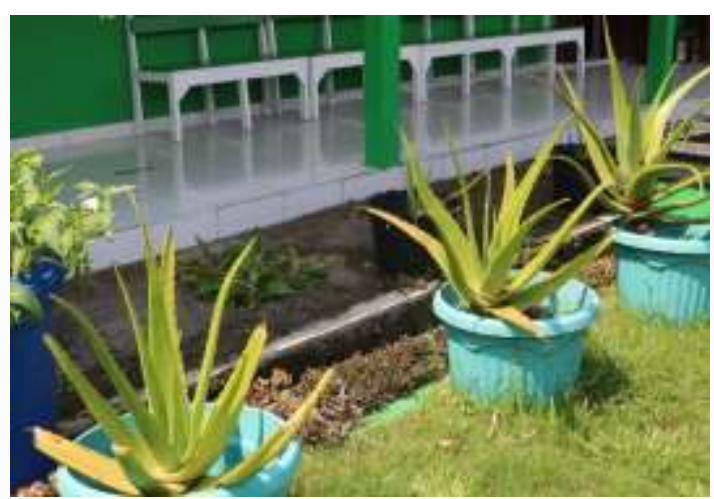

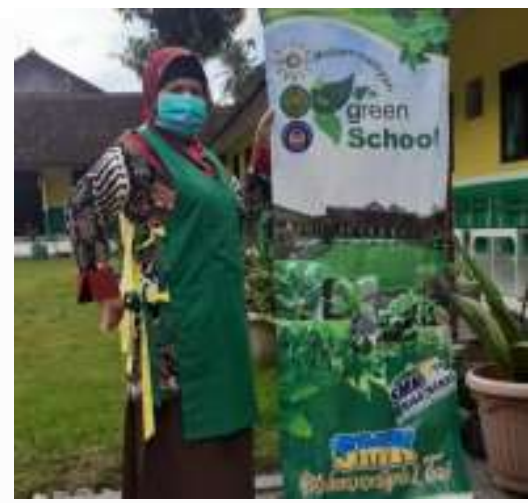

$\mathrm{b}$

Gambar 5. Tanaman lidah buaya (a) dan banner kampanye MGS di SMKM 2 Turi (b)

Untuk mendukung pemanfaatan lingkungan sekolah dan memberikan pembelajaran kepada siswa untuk berwirausaha juga diusahakan budidaya ikan dalam ember (budikdamber). Budikdamber yang dilakukan dengan sistem aquaponik, memiliki kelebihan antara lain mudah dilakukan, tidak butuh lahan yang luas, hemat dalam penggunaan air, tidak membutuhkan modal yang besar, dapat mencukupi kebutuhan gizi, dan memberikan keuntungan ekonomi (Nursandi, 2018; Suryana et al., 2021). Budikdamber di SMKM 2 Turi menggunakan wadah berupa drum plastik bekas yang pada bagian bawahnya dipasang kran air, dan pada bagian tutupnya dibuat lubang-lubang tanam untuk meletakkan gelas plastik sebagai tempat penanaman kangkung (Gambar 6a).

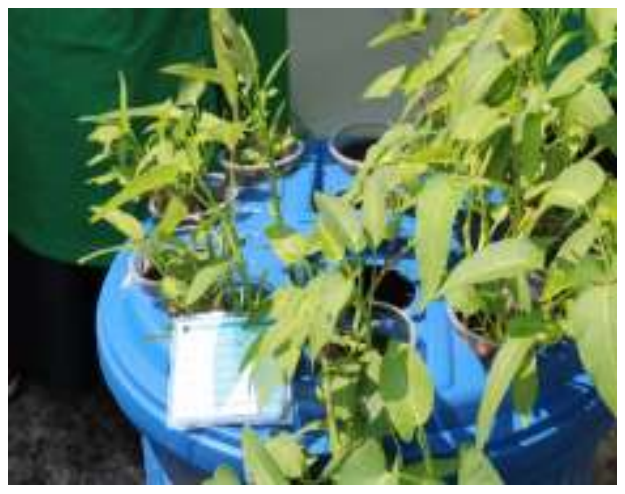

a

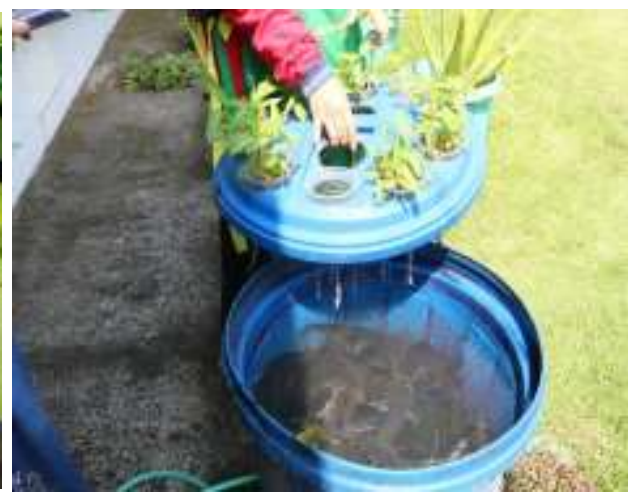

b

Gambar 6. Budikdamber pendukung MGS di SMKM 2 Turi; kangkung (a) dan lele (b) 
Ikan yang diusahakan dalam budikdamber di SMKM 2 Turi adalah ikan lele karena dilihat dari sisi pertumbuhan dan waktu panennya relatif cepat 1,5-2 bulan (Susetya, 2018), potensi pengembangannya sangat prospektif karena permintaan masyarakat terus bertambah (Saputri \& Rachmawatie, 2020), dan mudah dalam budidayanya (Nursandi, 2018). Dalam setiap drum plastik diisi sekitar 75 ekor bibit lele, dengan diberi pakan berupa pelet. Agar pertumbuhannya cepat dan ikannya sehat, air dalam drum diganti setiap 2 minggu sekali dengan cara membuang air melalui kran pembuangan di bagian bawah, dan mengisikan air kembali dengan membuka tutup pada bagian atasnya. Dengan pemberian pakan dan penggantian air yang rutin, lele dalam drum dapat dipanen setiap 1,5-2,5 bulan sekali.

Untuk menjamin keberhasilan dan keberlanjutan pelaksanaan MGS di SMKM 2 Turi, dilakukan pendampingan dan monitoring lapangan secara rutin. Pendampingan dilakukan dengan memberikan pengarahan dan konsultasi kepada mitra (Gambar 7).

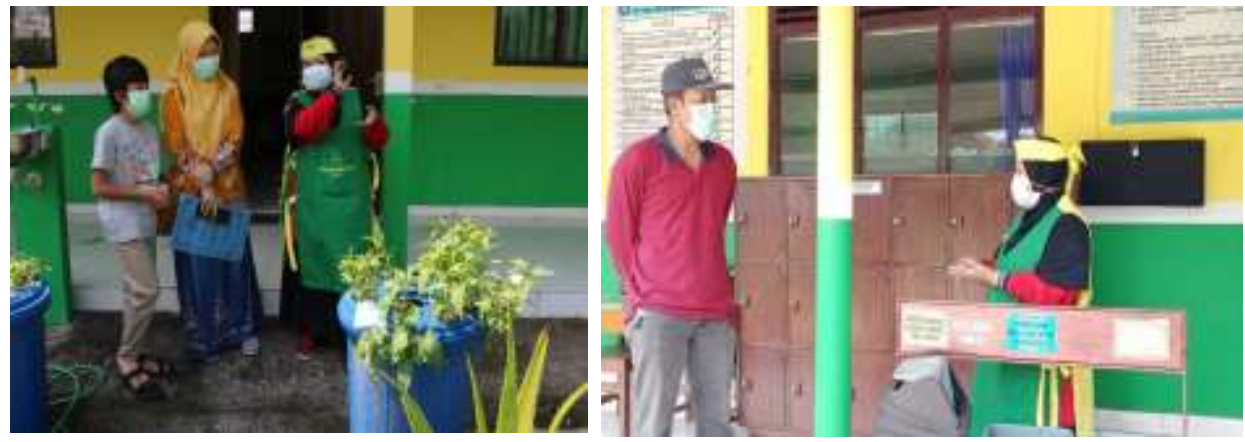

Gambar 7. Pendampingan pelaksanaan MGS di SMKM 2 Turi

Monitoring dan evaluasi dilakukan dengan mengunjungi sekolah untuk melihat secara langsung perkembangan pelaksanaan MGS di SMKM 2 Turi. Jika ada kegiatan yang kurang sesuai dengan rencana atau kurang sesuai, diberikan evaluasi dan masukan agar dapat berjalan lebih baik (Gambar 8a). Dengan pengelolaan yang baik dan pendampingan dari UMY, pelaksanaan MGS di SMKM 2 Turi dapat berjalan dengan baik dan menghasilkan lingkungan sekolah yang asri dan nyaman. Berbagai kegiatan $M G S$ yang sudah dilakukan dan hasil yang diperoleh dapat dimanfaatkan sebagai media pendidikan karakter bagi para siswa (Gambar 8b). Selain itu, penataan lingkungan melalui MGS ini dapat menjadi langkah awal bagi SMKM 2 Turi untuk menuju Sekolah Adiwiyata.

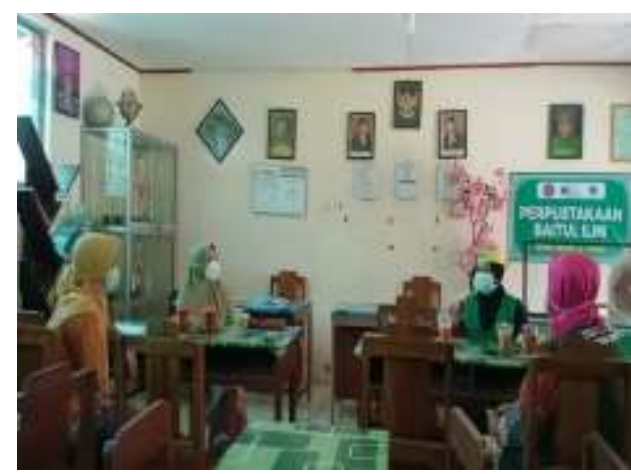

a

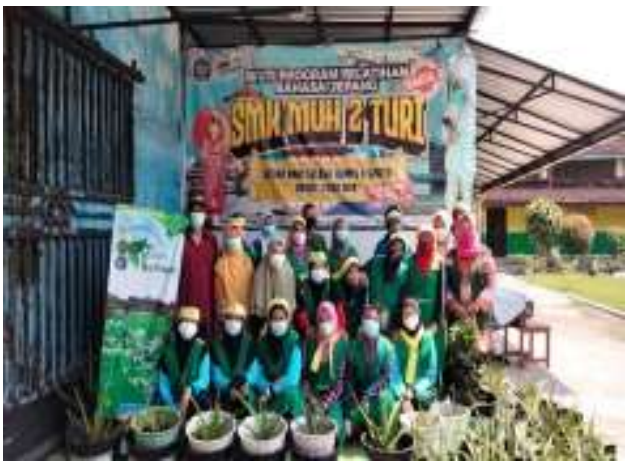

$\mathrm{b}$

Gambar 8. Monitoring (a) dan hasil kegiatan bersama MGS di SMKM 2 Turi (b)

\section{KESIMPULAN}

Program MGS di SMK Muhammadiyah 2 Turi sudah terlaksana dengan baik, dengan beberapa kegiatan yang dilakukan antara lain koordinasi, focus grup discussion, workshop, 
pelaksanaan, pendampingan dan monitoring. Dengan pendampingan dari UMY, program MGS dapat meningkatkan wawasan dan ketrampilan guru dan siswa SMK Muhammadiyah 2 Turi dalam menjalankan MGS, lingkungan sekolah mampu menyediakan bahan dan ruang belajar bagi siswa, serta menjadi lebih kondusif dan produktif sehingga dapat menjadi sebagai media pendidikan karakter dan peduli terhadap lingkungan yang bersih dan sehat, serta menjadi langkah awal menuju Sekolah Adiwiyata.

\section{UCAPAN TERIMA KASIH}

Ucapan terima kasih dan penghargaan disampaikan kepada Pimpinan UMY yang sudah banyak mendukung kegiatan pengabdian kepada masyarakat, Kepala Sekolah, siswa, dan guru SMK Muhammadiyah 2 Turi sebagai masayarakat mitra yang telah berperan aktif dalam program pengabdian kepada masyarakat MGS, serta Pimpinan Cabang Muhammadiyah dan Majelis Dikdasmen PCM Turi yang sudah memberikan dukungan, serta semua pihak yang telah berpartisipasi dalam pengabdian kepada masyarakat ini.

\section{DAFTAR PUSTAKA}

Andi Ikhsan, Sulaiman, \& Ruslan. (2017). Pemanfaatan Lingkungan Sekolah Sebagai Sumber Belajar Di Sd Negeri 2 Teunom Aceh Jaya. Jurnal Ilmiah Pendidikan Guru Sekolah Dasar, 2(1), 1-11. https://www.neliti.com/id/publications/187661/pemanfaatan-lingkungan-sekolahsebagai-sumber-belajar-di-sd-negeri-2-teunom-aceh

Ashabul, K. (2013). Jaminan konstitusional terhadap hak atas lingkungan hidup di indonesia. AlDaulah, 2(2), 143-159.

Asnudin, A. (2010). Pendekatan Partisipatif Dalam Pembangunan Proyek Infrastruktur Perdesaan di Indonesia. Jurnal SMARTek, 8(3), 182-190.

Dikdasmenpwmdiy. $\quad$ (2021). SMK $\quad$ Muhammadiyah $2 \quad$ Turi. http://www.daposm.dikdasmenpwmdiy.or.id/beranda/detail_sekolah/20401310

Ginanjar, M. H. (2013). Urgensi Lingkungan Pendidikan Sebagai Mediasi Pembentukan Karakter Peserta Didik. Edukasi Islami Jurnal Pendidikan Islam, 02, 376-396. https://jurnal.staialhidayahbogor.ac.id/index.php/ei/article/view/37

Haryati, D. (2016). Efektivitas Pemanfaatan Lingkungan Sekolah Sebagai Sumber Belajar Terhadap Hasil Belajar Ipa Peserta Didik Kelas Iv SD Inpres BTN IKIP I Makassar. AULADUNA: Jurnal Pendidikan Dasar Islam, 3(2), 80-96. https://doi.org/10.24252/auladuna.v3i2a4.2016

Majumdar, J. (2010). Greening TVET: Connecting the Dots in TVET for Sustainable Development. The 16th IVETA-CPSC International Conference on "Education for Sustainable Development in TVET" Manila, Philippines.

Mardliyah, K., Hambali, \& Zahirman. (2016). Pengaruh Gerakan Go Green School Terhadap Pembentukan Karakter Peduli Lingkungan Siswa Di Mtsn Model Kuok Kecamatan Kuok Kabupaten Kampar. AULADUNA: Jurnal Pendidikan Dasar Islam, 3(2), 1-15. http://journal.uin-alauddin.ac.id/index.php/auladuna/article/view/5104

Muslim, A. (2007). Pendekatan Partisipatif Dalam Pemberdayaan Masyarakat. Aplikasi Ilmu-Ilmu Agama, VIII(2), 89-103. https://doi.org/10.1177/0734282911435461

Nursandi, J. (2018). Budidaya Ikan Dalam Ember "Budikdamber" dengan Aquaponik di Lahan Sempit Fish Culture in a "Budicdamber "Bucket with Aquaponics on Narrow Lands. 2013, 129136.

Rahmah, U. (2020). Pengaruh Penerapan Green School Terhadap Minat Belajar Siswa di SMPN 26 Surabaya. At-Turāś, iv(2), 153-171. https://doi.org/10.12681/osj.23448

Rinaldy, R., Nulhaqim, S. A., \& Gutama, A. S. (2017). PProses Community Development Pada Program Kampung Iklim Di Desa Cupang Kecamatan Gempol Kabupaten Cirebon (Studi Kasus Program Bank Sampah Dalam Program Kampung Iklim). Prosiding Penelitian Dan Pengabdian Kepada Masyarakat, 4(2). https://doi.org/10.24198/jppm.v4i2.14344

Sagala, L. P. (2019). Implementation of Adiwiyata " Green School " in Chieving Education for 
Sustainable Development ( Case Study at Forestry Vocational School of Pekanbaru ). Kaunia, 15(2), 31. http://ejournal.uin-suka.ac.id/saintek/kaunia/article/view/1794

Sajiwo, R. G. (2019). Program Studi Ilmu Kesejahteraan Sosial Fakultas Dakwah dan Komunikasi UIN Sunan Kalijaga Yogyakarta Perilaku Hidup Bersih dan Sehat Keluarga Pemulung. Welfare : Jurnal Ilmu Kesejahteraan Sosial, 8(2), 203-218.

Saputri, S. A. D., \& Rachmawatie, D. (2020). Budidaya Ikan Dalam Ember: Strategi Keluarga Dalam Rangka memperkuat Ketahanan Pangan di Tengah Pandemi Covid-19. Jurnal Ilmu Pertanian Tirtayasa, 2(1), 102-109.

Sari, S. M., Ennimay, \& Tengku, A. R. (2019). Pemanfaatan Tanaman Obat Keluarga (TOGA) Pada Masyarakat. Dinamisia: Jurnal Pengabdian Kepada Masyarakat, 3, 1-7. https://doi.org/10.31849/dinamisia.v3i2.2833

Smkmuhaturi. (2021). SMK Muhammadiyah 2 Turi. SMK Muhammadiyah 2 Turi. https://www.smkmuhaturi.sch.id

Sumarmi. (2008). Sekolah Hijau Sebagai Alternatif Pendidikan Lingkungan Hidup Dengan Menggunakan Pendekatan Kontekstual. Jurnal Ilmu Pendidikan, 15(1), 19-25. http://journal.um.ac.id/index.php/jip/article/view/7/339

Suryana, A. A. H., Dewanti, L. P., \& Andhikawati, A. (2021). Penyuluhan Budidaya Ikan dalam Ember (Budikdamber) di Desa Sukapura Kecamatan Dayeuhkolot Kabupaten Bandung. Farmers: Journal of Community Services, 02(1), 4751.

Susetya, I.E., Z. A. H. (2018). Aplikasi Budikdamber ( Budidaya Ikan Dalam Ember ) Untuk Keterbatasan Lahan di Kota Medan. Abdimas Talenta, 3(2), 416-420.

Triyono, A. (2014). Pemberdayaan Masyarakat Melalui Community Development Program Posdaya (Pos Pemberdayaan Keluarga) Pt. Holcim Indonesia Tbk Pabrik Cilacap. KomuniT, VI(2), 111-121. http://journals.ums.ac.id/index.php/komuniti/article/view/2949

Wijaya, Y. D. (2019). Mengembangkan Karakter Dengan Program Sekolah Adiwiyata. Pena.Belajar.Kemdikbud. http://pena.belajar.kemdikbud.go.id/2019/12/mengembangkankarakter-dengan-program-sekolah-adiwiyata/ 